\begin{tabular}{|} 
Ambiente \& Água - An Interdisciplinary Journal of Applied Science \\
ISSN 1980-993X - doi:10.4136/1980-993X \\
www.ambi-agua.net \\
E-mail: ambi.agua@gmail.com
\end{tabular}

\title{
Estrutura comunitária de samambaias em mata ciliar: avaliação em gradiente de antropização
}

\author{
doi:10.4136/ambi-agua.1717 \\ Received: 28 Jul. 2015; Accepted: 26 Nov. 2015

\section{Ivanete Teresinha Mallmann*; Vinícius Leão da Silva; Jairo Lizandro Schmitt} \\ Universidade Feevale, Novo Hamburgo, RS, Brasil \\ Centro de Ciências da Saúde \\ *Autor correspondente: e-mail: ivamallmann@terra.com.br, \\ suicinivleao@hotmail.com,jairols@feevale.br
}

\section{RESUMO}

As matas ciliares são essenciais para a manutenção da biodiversidade e apresentam condições ecológicas favoráveis para o desenvolvimento de samambaias que são indicadoras de qualidade ambiental. Entretanto, essas matas vêm sofrendo impactos negativos relacionados principalmente à alta densidade demográfica, ao modelo de ocupação urbana e à expansão agrícola em áreas rurais. Neste trabalho, a qualidade ambiental da mata ciliar do rio Cadeia no Sul do Brasil foi avaliada utilizando parâmetros fitossociológicos da comunidade de samambaias do sub-bosque e o Protocolo de Avaliação Rápida da Qualidade de Hábitat (PARH). Foram alocadas 120 parcelas de $25 \mathrm{~m}^{2}$ distribuídas equitativamente entre três fragmentos (FI, FII, FIII). Foram inventariadas todas as espécies de samambaias herbáceas em cada unidade amostral. Para a análise da estrutura comunitária foram calculados os parâmetros de densidade, frequência, dominância relativa e o valor de importância da espécie (VI). A menor riqueza de espécies foi registrada no FIII (sete espécies). A composição florística é mais heterogênea e a riqueza é maior no FI no qual as parcelas apresentaram cobertura de plantas e a nota do PARH mais elevadas. A pontuação do PARH diminuiu com o aumento do grau de urbanização da matriz do entorno e os FI e FII foram classificados como naturais enquanto que o FIII como impactado. Considerando as quatro espécies com maior VI nos três fragmentos (que somam 69,11\% do VI no FI, 78,36\% no FII e 91,06\% no FIII) podese afirmar que a estrutura comunitária de samambaias sofre uma simplificação com o aumento da antropização.

Palavras-chave: bioindicadores, fitossociologia, fragmentação, Sul do Brasil, urbanização.

\section{Community structure of ferns in riparian forest: evaluation in anthropization gradient}

\begin{abstract}
Riparian forests are essential to the maintenance of biodiversity and foster the development of ferns that are indicators of environmental quality. However, these forests have been degraded due mainly to high population density, pattern of urban settlement and agricultural expansion in rural areas. This study evaluated the environmental quality of
\end{abstract}


riparian vegetation of the Cadeia River in Southern Brazil, using phytosociological parameters of the understory's fern community and a Rapid Assessment Protocol of Habitat Quality (RAPQH). One hundred and twenty plots of $25 \mathrm{~m}^{2}$ were equally distributed among three fragments (FI, FII, FIII). All species of herbaceous ferns were inventoried in each sample unit. We calculated parameters of density, frequency, relative dominance and importance value (IV) of species for the analysis of community structure. The lowest species richness was recorded at FIII (seven species). The floristic composition is more heterogeneous and richness is higher in FI, where the parcels had greater plant cover and RAPQH scores. The RAPQH score decreased with increasing degree of urbanization in the surrounding matrix and FI and FII were classified as "natural," while FIII was classified as "impacted." Considering the four species with the highest IV in the three fragments (totaling $69.11 \%$ of IV in the FI, $78.36 \%$ and $91.06 \%$ in FII and FIII respectively), it can be affirmed that the fern community structure is degraded with increasing anthropization.

Keywords: bioindicators, fragmentation, phytosociology, Southern Brazil, urbanization.

\section{INTRODUÇÃO}

A vegetação natural às margens dos rios constitui as matas ciliares (Mueller, 1996), que devido à interação das condições físicas com o meio biológico caracterizam-se pela heterogeneidade florística em diferentes intensidades (Rodrigues e Nave, 2000). O ambiente ciliar protege os corpos d'água, a biodiversidade, o solo e contribui positivamente para a produção primária do sistema lótico (Gregory et al., 1992; Oliveira-Filho e Ratter, 1995; Mueller, 1996), sendo definidas como áreas de preservação permanente (APPs) pelo Código Florestal Brasileiro (Brasil, 2012).

No entanto, mesmo sendo essenciais para a manutenção da biodiversidade e da qualidade ambiental, em áreas urbanizadas, as matas ciliares sofrem impactos negativos relacionados principalmente à alta densidade demográfica e ao modelo de ocupação urbana (Dias et al., 2014), enquanto que em áreas rurais são degradadas pela expansão agrícola desordenada (Rodrigues e Gandolfi, 2000).

Estimativas recentes sobre a flora mundial de samambaias apontam para aproximadamente 11.500 espécies (Moran, 2008). Para o Brasil são descritas 1.111 espécies, distribuídas principalmente nas regiões Sul e Sudeste, e para o estado do Rio Grande do Sul são listadas 331 (Prado e Sylvestre, 2015). Pelas matas ciliares apresentarem condições ecológicas para o desenvolvimento de samambaias (Windisch, 1996), os estudos sobre a estrutura comunitária dessas plantas nesse tipo de ambiente vêm sendo realizados no Brasil em diferentes tipos vegetacionais, com diferentes estados de conservação, empregando metodologias distintas.

Dentre os que utilizaram área amostral fixa, destacam-se os de Forsthofer e Athayde-Filho (2012) que registraram 17 espécies em 1,5 ha, em Nova Xavantina; o de Kreutz et al. (2009) com oito espécies em 1 ha de dois córregos da Bacia do rio Pindaíba, o de Kreutz e Athayde-Filho (2009) que registraram nove espécies em 2 ha em quatro ordens do córrego Caveira em Barra das Graças e o de Athayde-Filho e Agostinho (2005) que registraram 10 espécies, em área total de 1 ha em duas veredas, em Campinápolis, todos no estado do Mato Grosso. No Rio Grande do Sul, Diesel e Siqueira (1991) registraram 24 espécies em 0,18 ha na Bacia Hidrográfica do Rio dos Sinos e Mallmann e Schmitt (2014) registraram 26 espécies em 0,3 ha em três fragmentos do rio Cadeia na Bacia Hidrográfica do Rio Caí. Estes inventários evidenciam alta heterogeneidade quanto ao número de espécies de samambaias em diferentes matas ciliares e áreas amostradas.

As samambaias são um importante grupo vegetal com grande potencial bioindicador, já 
que tem sua diversidade e capacidade de colonização diretamente vinculados aos fatores abióticos do meio (Silva et al., 2011). Além disso, respondem de forma mais intensa às variações das condições ambientais como topografia ou fatores edáficos, quando comparadas a outros grupos vegetais florestais (Costa et al., 2005).

A incidência de gradientes ambientais de antropização permite avaliar os impactos das atividades humanas sobre os ecossistemas naturais (McDonnell e Pickett, 1990). Contudo, a avaliação da qualidade ambiental exige métodos e ferramentas eficientes (Rodrigues e Castro, 2008), que permitam uma análise conjunta de um maior número de variáveis bióticas.

Baseado na constatação de Mallmann e Schmitt (2014), de que a riqueza média de samambaias muda em diferentes fragmentos num gradiente crescente de urbanização do habitat matriz, os objetivos desse trabalho foram: (i) avaliar a qualidade ambiental de três fragmentos de mata ciliar ao longo do rio Cadeia utilizando um Protocolo de Avaliação Rápida da Qualidade de Hábitat (PARH); (ii) comparar a florística entre comunidades de samambaias do sub-bosque destes três fragmentos, bem como, (iii) analisar a estrutura fitossociológica de samambaias nas mesmas áreas.

\section{MATERIAL E MÉTODOS}

\section{1. Área de estudo}

O rio Cadeia é um dos maiores afluentes do rio Cá́, principal curso d'água da bacia hidrográfica do Caí, localizada no nordeste do Rio Grande do Sul, com uma área de 4.945,70 $\mathrm{km}^{2}$ (Rio Grande do Sul, 2010). De acordo com a classificação de Köeppen-Geiger, o clima na bacia é do tipo Cfa, ou seja, temperado úmido (C) com ocorrência de chuvas durante todos os meses do ano (f), sendo a temperatura média do mês mais quente superior a $22^{\circ} \mathrm{C}$ (a) (Peel et al., 2007).

Em Santa Maria do Herval, 37,58\% da área de preservação permanente do rio Cadeia está sem a cobertura vegetal prevista pelo Código Florestal (Sarmento et al., 2001). Nesse município, foram selecionados três fragmentos de mata ciliar (Figura1) para a realização do estudo:

Fragmento I (FI): situa-se no extremo leste de Santa Maria do Herval, distante $11 \mathrm{~km}$ do Centro da cidade (29 $31^{\prime} 1.02^{\prime \prime} \mathrm{S}$ e $50^{\circ} 54^{\prime} 46.78^{\prime} \mathrm{O}, 509 \mathrm{~m}$ de altitude). A mata ciliar tem 160 $\mathrm{m}$ de largura considerando a margem do rio e a borda do fragmento, sendo que dados históricos indicam que não há ação antrópica intensa sobre a vegetação há cerca de 70 anos. $\mathrm{O}$ FI está inserido em uma matriz rural, com baixa densidade demográfica.

Fragmento II (FII): situa-se a 2,4 km de distância do Centro do município (29॰30'14.20"S e 5058'28.13'O, 399 m de atitude) e está inserido em uma matriz suburbana, que apresenta a segunda maior densidade demográfica do município. Neste ponto o fragmento tem $39 \mathrm{~m}$ de largura entre a margem do rio e a borda da mata ciliar.

Fragmento III (FIII): situa-se no Centro (29³0’07.30”S e 5059’52.27’O, $388 \mathrm{~m}$ de altitude), em uma matriz urbana que apresenta a maior parte da população do município. $\mathrm{O}$ fragmento apresenta $55 \mathrm{~m}$ de largura da margem do rio até o limite florestal.

\subsection{Inventário florístico}

Para o levantamento dos dados florísticos nos FI, FII e FIII (Figura 1) foram realizadas excursões mensais, durante um ano, para registrar todas as espécies de samambaias herbáceas ocorrentes em uma área de $100 \times 10 \mathrm{~m}$, subdividida em 40 parcelas contíguas de $5 \times 5 \mathrm{~m}$ distribuídas equitativamente em duas transecções, paralelas ao curso do rio Cadeia, de acordo com o desenho amostral de Mallmann e Schmitt (2014). O material foi coletado seguindo a metodologia proposta por Windisch (1992). As espécies de samambaias coletadas foram identificadas utilizando literatura especializada, comparação com material determinado em 
herbário e consultas a especialistas. A classificação adotada para as famílias seguiu a proposta de Smith et al. (2008). Exemplares férteis representativos foram depositados no Herbarium Anchieta (PACA) do Instituto Anchietano de Pesquisa - Universidade do Vale do Rio dos Sinos, no Rio Grande do Sul, Brasil.

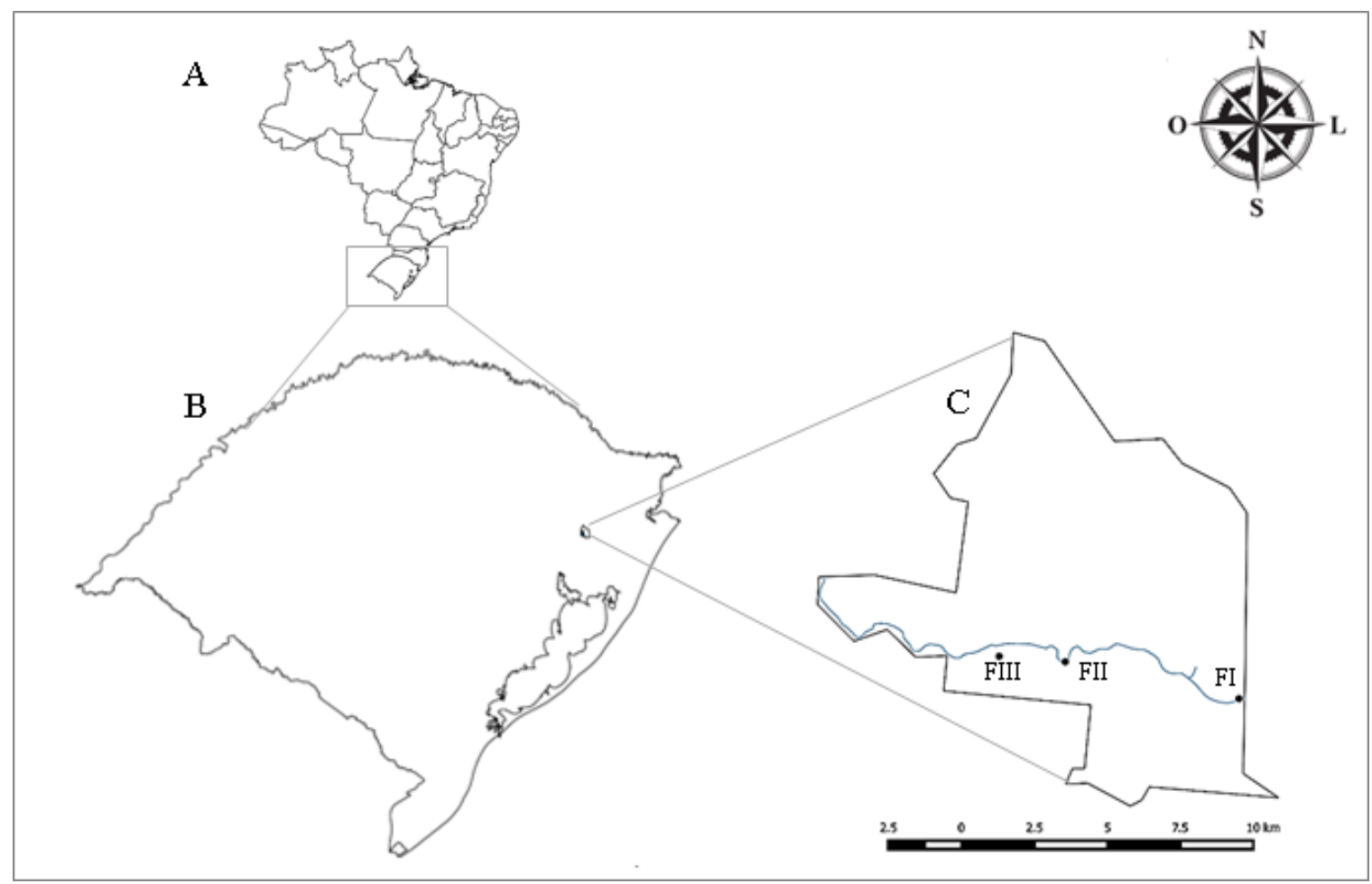

Figura 1. Mapa de localização dos fragmentos de mata ciliar (FI, FII e FIII) ao longo do rio Cadeia em Santa Maria do Herval (C), RS (B), Brasil (A).

\subsection{Estrutura comunitária}

Para a análise e comparação da estrutura da comunidade de samambaias herbáceas ocorrentes no sub-bosque dos fragmentos florestais, foram calculados os seguintes parâmetros fitossociológicos: densidade, frequência e dominância relativa, bem como, o valor de importância de acordo com Vuono (2002) adaptado por Condack e Sylvestre (2009) para esse grupo vegetal.

\subsection{Protocolo de Avaliação Rápida}

O Protocolo de Avaliação Rápida da Qualidade de Hábitat (PARH) é uma ferramenta criada para o monitoramento ambiental de sistemas hídricos e os ecossistemas que os abrangem (Bizzo et al., 2014). O PARH aplicado nos três fragmentos estudados foi modificado da proposta de Hannaford et al. (1997) e da Agência de Proteção Ambiental de Ohio (EUA) - (USEPA, 1987 adaptado por Callisto et al., 2002). Dos 20 parâmetros do PARH considerados neste estudo, os 10 primeiros analisam as características dos fragmentos e o nível dos impactos decorrentes da antropização e os demais, as condições de hábitat e o nível de conservação das condições naturais, sendo: 1: Ocupação das margens do rio (principal atividade); 2: Erosão das margens e assoreamento do rio; 3: Alterações antrópicas; 4: Cobertura vegetal no leito do rio; 5: Odor da água; 6: Oleosidade da água; 7: Transparência da água; 8: Odor do sedimento; 9: Oleosidade do sedimento; 10: Tipo de fundo; 11: Diversificação de hábitats submersos; 12: Tipos de substrato; 13: Percentual de deposição de lama; 14: Percentual de depósitos sedimentares; 15: Alterações no canal do rio; 16: Características do fluxo d'água; 17: Características da vegetação ripária; 18: Estabilidade das 
margens; 19: Extensão de mata ciliar; 20: Plantas aquáticas. As Pontuações aplicadas aos parâmetros do Protocolo de Avaliação Rápida da Diversidade de Hábitats utilizado para a avaliação dos fragmentos foram: parâmetros 1 - 10: pontuação máxima (5: situação natural), intermediária (3: alteração leve) e mínima: (0: alteração severa); parâmetros 11 - 20: pontuação máxima (5: situação natural), intermediária (3: alteração leve; 2: alteração mediana) e mínima (0: alteração severa). O somatório dos pontos de cada parâmetro do PARH classifica os trechos avaliados em: impactado ( 0 a 40 pontos); alterado (41 a 60 pontos) e natural (61 a 100 pontos).

\subsection{Análise estatística}

As médias de riqueza, abundância e área de cobertura de samambaias herbáceas por parcela no FI, FII e FIII foram comparadas entre si, utilizando o programa estatístico BioEstat versão 5.2. Para verificar a normalidade dos dados, utilizou-se o teste de Shapiro-Wilk. Como a hipótese de normalidade não foi satisfatória, os dados foram analisados pelo teste não paramétrico de Kruskal-Wallis, seguido pelo teste de Dunn, a 5\% de probabilidade.

Os dados de composição de espécies nos FI, FII e FIII foram submetidos à Análise de Coordenadas Principais (PCoA) para a visualização da similaridade florística em diagrama, adotando-se o índice de Sørensen-Dice. A Análise de Componentes Principais (PCA) foi utilizada na representação das relações entre as unidades amostrais com os parâmetros de riqueza, número de indivíduos e cobertura $\left(\mathrm{m}^{2}\right)$ de samambaias por parcela e a pontuação total do PARH. Ambas as análises foram conduzidas no software PAST (Paleontological Statistics Software Package for Education and Data Analysis), versão 2.17 (Hammer et al., 2001).

\section{RESULTADOS E DISCUSSÃO}

Os resultados da aplicação do PARH no rio Cadeia em Santa Maria do Herval classificaram os FI e FII como naturais e o FIII como impactado (Figura 2). Dessa forma, o nível de degradação de cada ponto avaliado acompanhou o grau de urbanização do entorno, evidenciando um gradiente decrescente de qualidade ambiental a partir do FI (pontuação - FI: 87; FII: 73 e FIII: 34).

Entretanto, a expressiva diferença do FIII em relação aos demais se deve também ao represamento desse trecho desde 1945, o que provocou modificações no canal do rio e no fluxo d'água. Estas alterações estão relacionadas à ocupação, erosão e estabilidade das margens; à deposição de lama e sedimentos; à redução dos tipos de substrato; além da homogeneidade de habitats submersos (Figura 2). De acordo com Rodrigues et al. (2010), obras de engenharia ou alterações no canal do rio causam a redução na densidade e diversidade de espécies aquáticas. Outro indicador do maior impacto no FIII é a presença de bancos de macrófitas, que são espécies flutuantes livres, cujo desenvolvimento está atrelado à menor velocidade da água (Thomaz, 2002), ao aumento da turbidez pela concentração de material em suspensão e outros atributos (Thomaz et al., 2004) que limitam sua ocorrência a este trecho.

Em contraponto, nos FI e FII onde o rio tem maior declividade, o fluxo d'água apresenta corredeiras que são indicadoras de alta qualidade do hábitat e da diversidade da fauna (Barbour et al., 1999). Estes fatores, dentre outros, influenciam inclusive na riqueza, estrutura e distribuição de espécies epifíticas em matas ciliares (Bonnet, 2006; Kersten e Kuniyoschi, 2009), como já constatado por Mallmann e Schmitt (2014) que registraram maior riqueza de samambaias epifíticas no FI e FII em relação ao FIII do presente estudo. Por fim, a melhor conservação da mata ciliar nos FI e FII confere proteção e estabilidade às margens do rio, o que contribui para a classificação desses pontos como sendo naturais, fato que também já foi descrito por Barrella et al. (2000). 


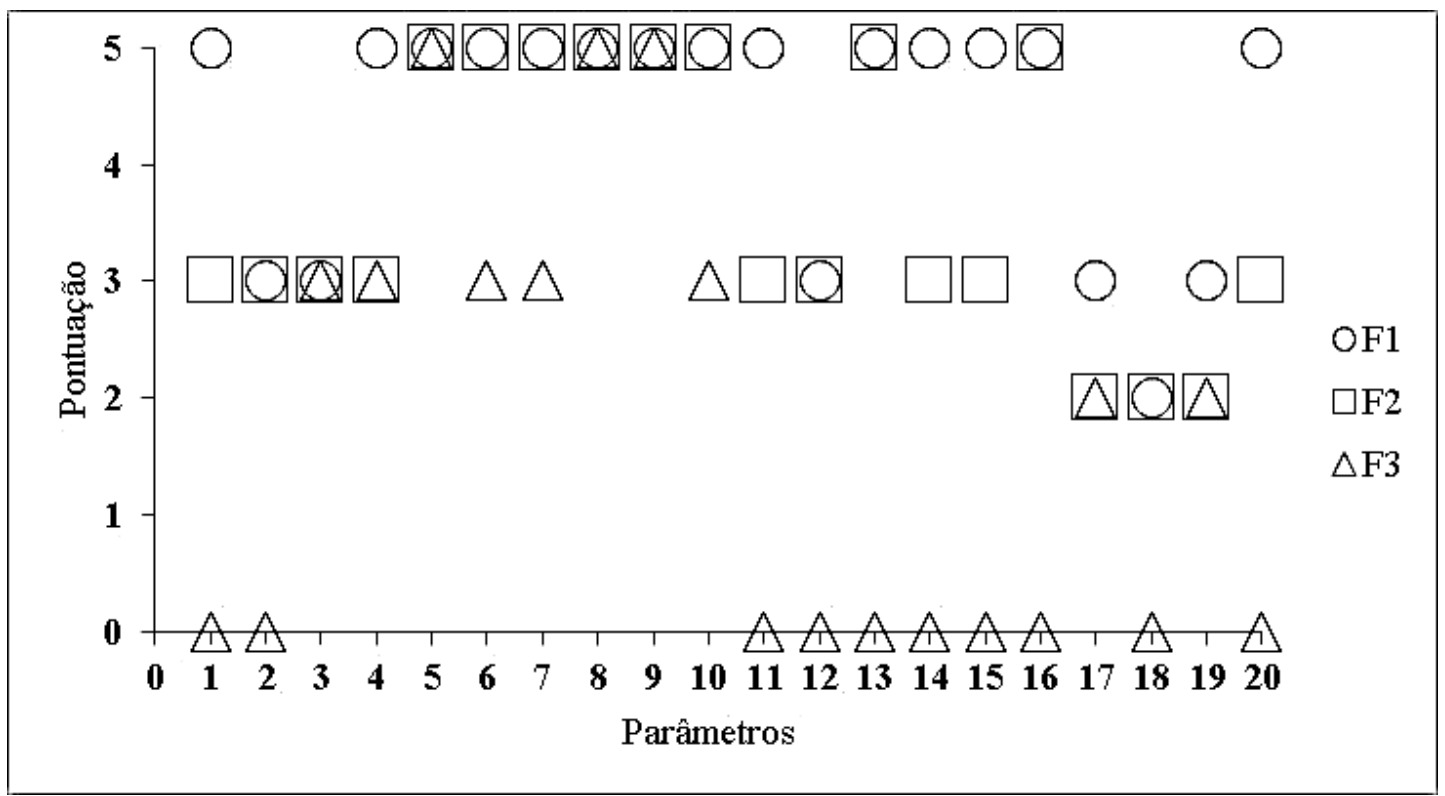

Figura 2. Pontuação aplicada aos parâmetros do Protocolo de Avaliação Rápida da Diversidade de Hábitats utilizado para a avaliação dos Fragmentos I (FI: ○), II (FII: $\square$ ) e III (FIII: $\Delta$ ) do rio Cadeia em Santa Maria do Herval. Parâmetros 1 - 10: pontuação máxima (5: situação natural), intermediária (3: alteração leve) e mínima: (0: alteração severa); parâmetros 11 - 20: pontuação máxima (5: situação natural), intermediária (3: alteração leve; 2: alteração mediana) e mínima (0: alteração severa). A relação entre o número e nome dos parâmetros pode ser encontrada no Material e Métodos.

$\mathrm{Na}$ análise da estrutura comunitária, verificou-se que no FI a riqueza específica total foi de 18 espécies variando de três a 10 por parcela, com média de 5,9 $( \pm 1,67)$ e as espécies com maior área de cobertura foram Megalastrum inaequale, Dicksonia sellowiana, Pteris deflexa e Ctenitis submarginalis, que somadas representam $90,68 \%$ do total da comunidade. Consequentemente estas mesmas espécies apresentaram os maiores valores de importância, somando $70,97 \%$ do total. Embora Dennstaedtia globulifera e P. deflexa apresentassem abundância menor que Thelypteris recumbens, o VI de importância mais elevado dessas duas espécies decorreu de valores expressivamente maiores de cobertura (Tabela 1). O mesmo ocorreu com $D$. sellowiana que apresentou baixa $D R$, devido ao número reduzido de indivíduos, mas foi a terceira espécie em valor de importância (VI) em virtude da sua elevada área de cobertura. Trata-se de uma espécie com folhas grandes, com até cerca de 2,40 $\mathrm{m}$ de comprimento (Fernandes, 2000).

Das espécies exclusivas encontradas no FI, Vandenboschia radicans é classificada como hemiepífita ou epipétrica, e ocorre geralmente em florestas fechadas e úmidas (Windisch, 2014). Da mesma forma, Eupodium kaulfussii é classificada como terrícola, sendo característica de ambientes montanhosos e úmidos (Tryon e Tryon, 1982) e integra a lista de espécies ameaçadas do Rio Grande do Sul na categoria vulnerável (Rio Grande do Sul, 2014). O registro dessas espécies evidencia o alto grau de conservação deste fragmento, corroborando com os resultados do PARH.

No FII foram registradas 21 espécies, com riqueza variando de 0 a 10 espécies por parcela e média de 4,7 $( \pm 2,26)$. Em relação à cobertura, Blecnhum brasiliense se destacou com 55,01\% da cobertura total, seguido de Ctenitis submarginalis e Deparia petersenii. O alto valor de cobertura de $B$. brasiliense se deve ao fato de ser uma espécie subarborescente, com cáudice ereto e robusto, com até $60 \mathrm{~cm}$ de altura e folhas de até 1,3 $\mathrm{m}$ de comprimento (Franz e Schmitt, 2005). Estas três espécies somam 81,84\% da cobertura total nesta área. As espécies B. brasiliense, C. submarginalis, D. petersenii e Anemia phyllitidis apresentaram os 
maiores VI representando 72,12\% do total (Tabela 2).

Tabela 1. Parâmetros fitossociológicos para as espécies de samambaias amostradas no sub-bosque do Fragmento I da mata ciliar do Rio Cadeia em Santa Maria do Herval, RS. Ni- número de indivíduos, Ui - número de parcelas de ocorrência da espécie, DR\%- densidade relativa, FR\%- frequência relativa, DoR\%- dominância relativa, VI- valor de importância.

\begin{tabular}{lccccccc}
\hline Espécie & $\mathrm{Ni}$ & $\mathrm{Ui}$ & $\mathrm{DR} \%$ & $\mathrm{FR} \%$ & DoR\% & VI \\
\hline Megalastrum inaequale (Kaulf. ex Link) A.R.Sm. \& & 436 & 39 & 38,58 & 16,32 & 45,82 & 33,57 \\
R.C.Moran & 240 & 35 & 21,24 & 14,64 & 10,74 & 15,54 \\
Ctenitis submarginalis (Langsd. \& Fisch.) Ching & 35 & 23 & 3,1 & 9,62 & 23,05 & 11,92 \\
Dicksonia sellowiana Hook & 70 & 30 & 6,19 & 12,55 & 11,07 & 9,94 \\
Pteris deflexa Link & 125 & 10 & 11,06 & 4,18 & 0,53 & 5,26 \\
Thelypteris recumbens (Rosenst.) C.F.Reed & 35 & 10 & 3,1 & 4,18 & 3,68 & 3,65 \\
Dennstaedtia globulifera (Poir.) Hieron. & 28 & 18 & 2,48 & 7,53 & 1,21 & 3,74 \\
Polystichum platylepis Fée & 47 & 11 & 4,16 & 4,6 & 1,54 & 3,43 \\
Diplazium herbaceum Fée & 33 & 10 & 2,92 & 4,18 & 0,09 & 2,4 \\
Vandenboschia radicans (Sw.) Copel. & 27 & 10 & 2,39 & 4,18 & 0,52 & 2,36 \\
Blechnum acutum (Desv.) Mett. & 16 & 11 & 1,42 & 4,6 & 0,17 & 2,06 \\
Thelypteris riograndensis (Lindm.) C.F.Reed & 12 & 9 & 1,06 & 3,77 & 0,1 & 1,64 \\
Anemia phyllitidis (L.) Sw. & 10 & 9 & 0,88 & 3,77 & 0,06 & 1,57 \\
Asplenium claussenii Hieron. & 7 & 6 & 0,62 & 2,51 & 1,36 & 1,5 \\
Dennstaedtia obtusifolia (Willd.) T.Moore & 5 & 5 & 0,44 & 2,09 & 0,04 & 0,86 \\
Campyloneurum nitidum (Kaulf.) C.Presl & 2 & 1 & 0,18 & 0,42 & 0,01 & 0,2 \\
Asplenium gastonis Fée & 1 & 1 & 0,09 & 0,42 & 0,01 & 0,17 \\
Thelypteris opposita (Vahl) Ching & 1 & 1 & 0,09 & 0,42 & 0 & 0,17 \\
Eupodium kaulfussii (J.Sm.) J.Sm. & $\mathbf{1 1 3 0}$ & & & & \\
\hline Total & & & & & \\
\hline
\end{tabular}

Ctenitis submarginalis foi ainda a espécie que esteve entre aquelas de maior VI independente do fragmento de ocorrência. De acordo com Mynssen e Windisch (2004), é uma espécie tanto de sub-bosque sombreado quanto mais exposta à luz solar, o que facilitaria sua distribuição mais generalizada, e nesse sentido aumentaria sua capacidade competitiva.

Há evidências botânicas da decrescente integridade ambiental a partir do fragmento I. A exemplo disso, B. brasiliense foi exclusivo do FII, que é menos preservado que o FI de acordo com a nota obtida no PARH. Essa espécie também foi encontrada em ambientes alterados nos estudos desenvolvidos por Paciencia e Prado (2005) e Silva (2013). O mesmo ocorreu com Macrothelypteris torresiana, que também foi exclusiva do FII sendo uma espécie genuinamente encontrada em ambientes alterados ou abertos, como beira de estradas e trilhas, terrenos baldios de áreas urbanas e florestas secundárias (Salino, 2000).

Cyathea atrovirens ocorreu apenas no FII. Essa espécie é preferencialmente encontrada em locais abertos e iluminados, tais como áreas degradadas ou clareiras florestais (Lorscheitter et al., 1999). Tryon e Tryon (1982) reportaram a ocorrência de C. atrovirens em áreas elevadas da Serra do Mar no sudeste brasileiro, destacando a sobrevivência de indivíduos em locais onde toda a cobertura do solo foi destruída pela ação de queimadas.

Asplenium gastonis e Campyloneurum nitidum ocorreram tanto em FI quanto FII, com 
VI baixos (Tabelas 1 e 2) e isso está relacionado diretamente ao fato de serem espécies preferencialmente epifíticas ou rupícolas e, neste caso, limitando seu desenvolvimento no estrato herbáceo.

Em contrapartida, Dicksonia sellowiana, que consta na lista de espécies ameaçadas do Rio Grande do Sul (Rio Grande do Sul, 2014), obteve o terceiro maior VI no fragmento I $(11,92)$ enquanto no fragmento II ficou na $18^{\mathrm{a}}$ posição $(\mathrm{VI}=0,32)$, com apenas um indivíduo. Essa espécie desempenha um papel fundamental como forófito de epífitos no sub-bosque das florestas, sendo que algumas epífitas são exclusivas ou ocorrem preferencialmente sobre seu cáudice (Fraga et al., 2008). Ademais, considerando o ritmo lento de crescimento de D. sellowiana, estimado por Schmitt et al. (2009) em 5,6 cm por ano, e a altura máxima de 6 $\mathrm{m}$ registrada no fragmento I, pode-se concluir que o fragmento possui mais de 100 anos.

Tabela 2. Parâmetros fitossociológicos para as espécies de samambaias amostradas no sub-bosque do Fragmento II da mata ciliar do Rio Cadeia em Santa Maria do Herval, RS: Ni- número de indivíduos, Ui - número de parcelas de ocorrência da espécie, DR\%- densidade relativa, FR\%- frequência relativa, DoR\%- dominância relativa, VI- valor de importância.

\begin{tabular}{|c|c|c|c|c|c|c|}
\hline Espécie & $\mathrm{Ni}$ & Ui & $\mathrm{DR} \%$ & $\mathrm{FR} \%$ & DoR \% & VI \\
\hline Blechnum brasiliense Desv. & 145 & 17 & 9,51 & 8,9 & 55,01 & 24,47 \\
\hline Ctenitis submarginalis (Langsd. \& Fisch.) Ching & 475 & 33 & 31,15 & 17,28 & 15,42 & 21,28 \\
\hline Deparia petersenii (Kunze) M.Kato & 377 & 23 & 24,72 & 12,04 & 11,41 & 16,06 \\
\hline Anemia phyllitidis (L.) Sw. & 198 & 31 & 12,98 & 16,23 & 1,73 & 10,31 \\
\hline Thelypteris riograndensis (Lindm.) C.F.Reed & 170 & 21 & 11,15 & 10,99 & 2,8 & 8,31 \\
\hline Thelypteris opposita (Vahl) Ching & 51 & 12 & 3,34 & 6,28 & 2,26 & 3,96 \\
\hline Megalastrum inaequale (Kaulf. ex Link) A.R.Sm. \& R.C.Moran & 16 & 9 & 1,05 & 4,71 & 2,33 & 2,7 \\
\hline Cyathea atrovirens (Langsd. \& Fisch.) Domin & 15 & 7 & 0,98 & 3,66 & 3,01 & 2,55 \\
\hline Macrothelypteris torresiana (Gaudich.) Ching & 14 & 9 & 0,92 & 4,71 & 1,67 & 2,43 \\
\hline Thelypteris dentata (Forssk.) E.P.St.John & 24 & 9 & 1,57 & 4,71 & 0,78 & 2,35 \\
\hline Alsophila setosa Kaulf. & 2 & 2 & 0,13 & 1,05 & 1,84 & 1,01 \\
\hline Campyloneurum nitidum (Kaulf.) C.Presl & 6 & 4 & 0,39 & 2,09 & 0,1 & 0,86 \\
\hline Asplenium gastonis Fée & 14 & 2 & 0,92 & 1,05 & 0,21 & 0,73 \\
\hline Pteris deflexa Link & 3 & 2 & 0,2 & 1,05 & 0,69 & 0,65 \\
\hline Pecluma truncorum (Lindm.) M.G.Price & 3 & 2 & 0,2 & 1,05 & 0,08 & 0,44 \\
\hline Blechnum acutum (Desv.) Mett. & 3 & 2 & 0,2 & 1,05 & 0,06 & 0,43 \\
\hline Doryopteris lorentzii (Hieron.) Diels & 3 & 2 & 0,2 & 1,05 & 0,04 & 0,43 \\
\hline Dicksonia sellowiana Hook & 1 & 1 & 0,07 & 0,52 & 0,38 & 0,32 \\
\hline Rumohra adiantiformis (G.Forst.) Ching & 3 & 1 & 0,2 & 0,52 & 0,13 & 0,28 \\
\hline Dennstaedtia globulifera (Poir.) Hieron. & 1 & 1 & 0,07 & 0,52 & 0,03 & 0,21 \\
\hline Adiantum raddianum C.Presl & 1 & 1 & 0,07 & 0,52 & 0,01 & 0,2 \\
\hline Total & 1525 & & & & & \\
\hline
\end{tabular}


No FIII a riqueza total foi de sete espécies variando de zero a cinco, com média de 1,95 $( \pm 1,06)$. Ctenitis submarginalis, Dennstaedtia globulifera e Thelypteris scabra apresentaram o maior valor de cobertura ( $83 \%$ da cobertura total da área) e somaram $78,78 \%$ do total do valor de importância (Tabela 3).

Tabela 3. Parâmetros fitossociológicos para as espécies de samambaias amostradas no sub-bosque do Fragmento III da mata ciliar do Rio Cadeia em Santa Maria do Herval, RS: Ni- número de indivíduos, Ui - número de parcelas de ocorrência da espécie, DR\%-densidade relativa, FR\%- frequência relativa, DoR\%- dominância relativa, VI - valor de importância.

\begin{tabular}{lcccccc}
\hline Espécie & $\mathrm{Ni}$ & $\mathrm{Ui}$ & $\mathrm{DR} \%$ & $\mathrm{FR} \%$ & DoR\% & VI \\
\hline Ctenitis submarginalis (Langsd. \& Fisch.) Ching & 164 & 31 & 44,57 & 39,74 & 42,56 & 42,29 \\
Dennstaedtia globulifera (Poir.) Hieron. & 96 & 12 & 26,09 & 15,38 & 20,33 & 20,6 \\
Thelypteris scabra (C.Presl) Lellinger & 59 & 9 & 16,03 & 11,54 & 20,1 & 15,89 \\
Pteris deflexa Link & 16 & 7 & 4,35 & 8,97 & 15,1 & 9,47 \\
Anemia phyllitidis (L.) Sw. & 29 & 15 & 7,88 & 19,23 & 1,28 & 9,46 \\
Asplenium claussenii Hieron. & 3 & 3 & 0,82 & 3,85 & 0,27 & 1,64 \\
Deparia petersenii (Kunze) M.Kato & 1 & 1 & 0,27 & 1,28 & 0,37 & 0,64 \\
\hline Total & $\mathbf{3 6 8}$ & & & & \\
\hline
\end{tabular}

Considerando as quatro espécies com maior VI nos três fragmentos amostrais (que somam $69,11 \%$ dos indivíduos no FI, 78,36\% no FII e 91,06\% no FIII) pode-se sustentar que a estrutura comunitária de samambaias difere de acordo com as condições ambientais observadas através dos parâmetros do PARH, uma vez que, quanto mais severas as intervenções antrópicas no fragmento, maior foi a soma do VI para essas espécies naquele fragmento. Apesar disso, foram registradas espécies mais tolerantes à redução da qualidade ambiental, como Anemia phyllitidis, Ctenitis submarginalis, Dennstaedtia globulifera e Pteris deflexa que ocorreram nos três fragmentos.

No interior desses três fragmentos foram amostradas 29 espécies de samambaias pertencentes a 13 famílias, sendo que as de maior riqueza foram Thelypteridaceae com seis espécies, Dryopteridaceae (quatro) e Pteridaceae (três) que juntas representam $44,82 \%$ do total de espécies registradas.

Os fragmentos I e II apresentaram riqueza específica total similar (18 e 21 espécies respectivamente). Considerando o maior grau de perturbação do FII em relação ao FI, registraram-se diferenças na composição de espécies dos fragmentos, como o percentual de cobertura médio de samambaias por parcela que foi expressivamente maior no FI quando comparado com os demais (Tabela 4). Já no FIII, a riqueza total foi reduzida para apenas sete espécies.

Tabela 4. Riqueza média, abundância média e área de cobertura média por parcela das samambaias do sub-bosque em três fragmentos de mata ciliar (FI, II e III) do rio Cadeia em Santa Maria do Herval, RS. Médias com mesma letra são iguais $(P<0,01)$. $(\mathrm{S}=$ riqueza média de samambaias herbáceas por parcela; $\mathrm{Ni}$ = número de indivíduos por parcela; Área cobertura = média da área de cobertura de samambaias por parcela $\mathrm{em}^{2}$; $\mathrm{DP}=$ desvio-padrão).

\begin{tabular}{lccc}
\hline & S (DP) & Ni (DP) & $\begin{array}{c}\text { Área cobertura }\left(\mathrm{m}^{2}\right) \\
(\mathrm{DP})\end{array}$ \\
\hline Fragmento I & $5,9 \pm 1,67(\mathrm{a})$ & $28,25 \pm 13,78(\mathrm{a})$ & $31,78 \pm 17,20(\mathrm{a})$ \\
Fragmento II & $4,7 \pm 2,26(\mathrm{~b})$ & $38,12 \pm 43,54(\mathrm{a})$ & $13,48 \pm 22,97(\mathrm{~b})$ \\
Fragmento III & $1,95 \pm 1,06(\mathrm{c})$ & $9,2 \pm 9,21(\mathrm{~b})$ & $4,45 \pm 4,58(\mathrm{~b})$ \\
\hline
\end{tabular}


A Análise de Coordenadas Principais (PCoA) aproximou os fragmentos I e II, demonstrando que eles são mais homogêneos sob o ponto de vista florístico, em decorrência de um maior compartilhamento de espécies. A análise de similaridade entre os fragmentos indicou que internamente o FI é o que apresenta composição florística mais homogênea. Entretanto, externamente ele é mais heterogêneo em relação ao FII e FIII (Figura 3).

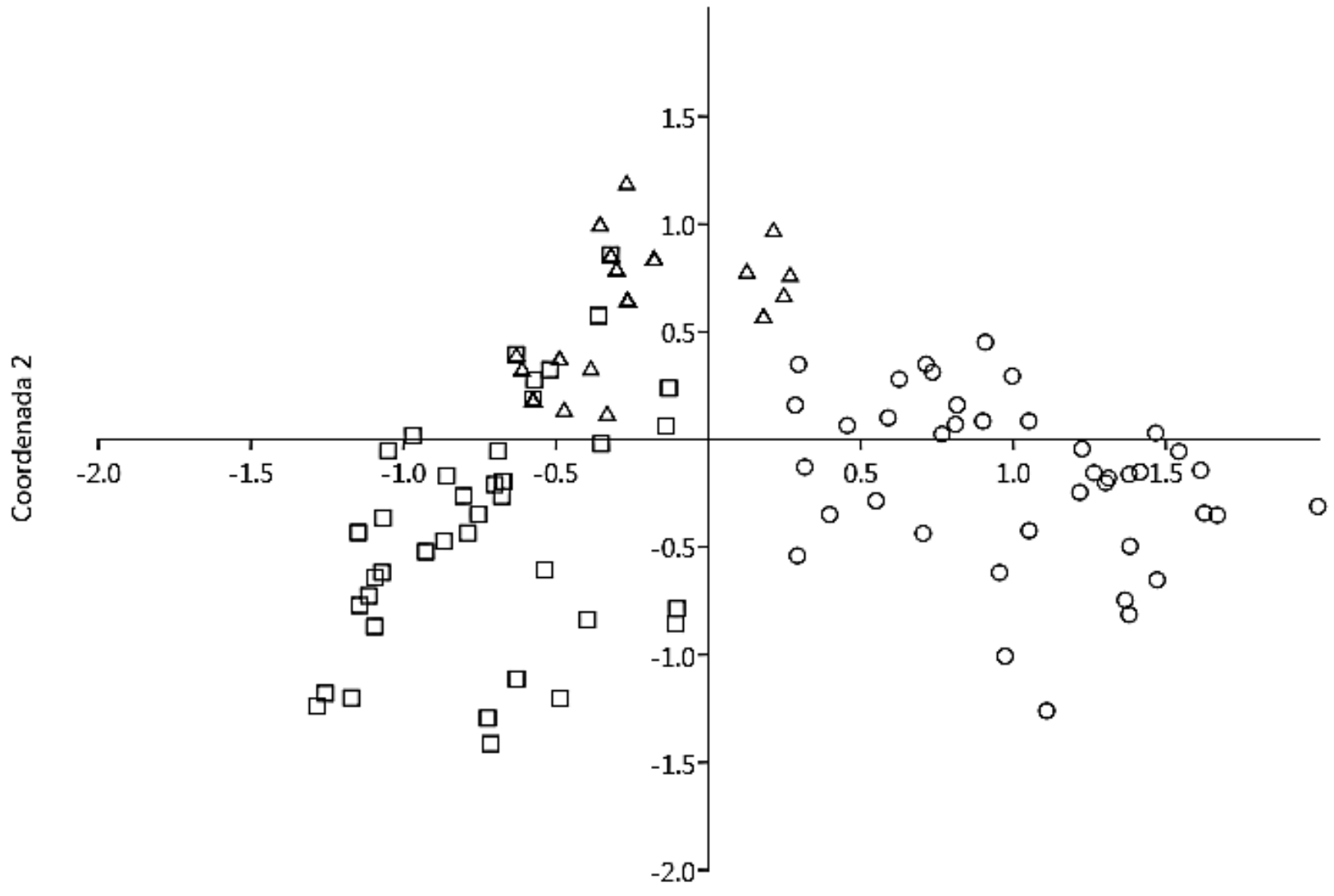

Coordenada 1

Figura 3. Análise de Coordenadas Principais (PCoA) entre as espécies de samambaias em suas respectivas parcelas: Fragmento I (०), Fragmento II ( $\square)$ e Fragmento III $(\Delta)$.

Os dois primeiros componentes da PCA explicaram $80,83 \%$ da variação e de maneira geral evidenciaram uma separação das parcelas de cada fragmento, em função das variáveis analisadas (Figura 4). Essa separação ocorreu principalmente pelo componente $1(64,05 \%)$, em que a riqueza de samambaias por parcela foi a variável mais relacionada $(0,55)$, seguida da pontuação do PARH $(0,50)$. Já pelo componente $2(16,78 \%)$, a variável com maior relação foi o número de indivíduos por parcela $(0,81)$, seguida da pontuação do PARH $(-0,55)$. A riqueza é maior nas parcelas nas quais a cobertura de plantas e a nota do PARH foram mais elevadas, demostrando que áreas mais antropizadas apresentam uma simplificação na estrutura da comunidade de samambaias herbáceas. O maior número de indivíduos associado ao FII pode ser devido ao fato de que espécies oportunistas e mais tolerantes podem ser favorecidas em função de alterações de condições ambientais locais. 


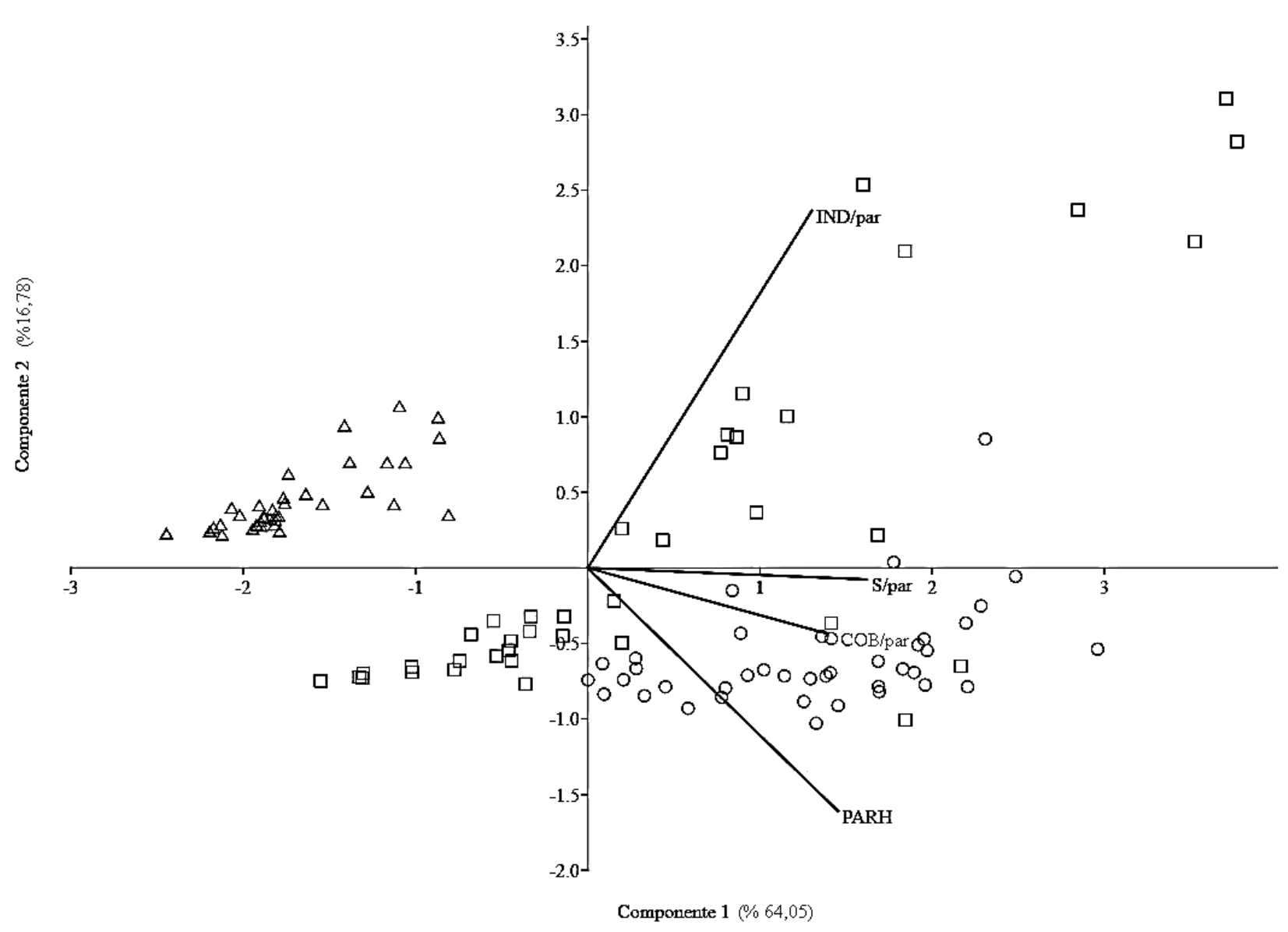

Figura 4. Análise de Componentes Principais (PCA), Fragmento I (०), Fragmento II ( $\square$ ) e Fragmento III $(\Delta)$. IND/par: Indivíduos por parcela; S/par: Riqueza por parcela; COB/par: Cobertura por parcela; PARH: Pontuação do Protocolo de Avaliação Rápida da Qualidade de Hábitat.

\section{CONCLUSÃO}

Embora se deva considerar a heterogeneidade característica das matas ciliares, mesmo em fragmentos muito próximos geograficamente como os do presente estudo, ficou evidente a simplificação da estrutura comunitária à medida que estes trechos perdem suas características naturais e têm sua qualidade ambiental diminuída de acordo com as categorias do PARH. Pode-se afirmar, inclusive, que quanto maior o grau de distúrbio de um fragmento, mais intensamente sua estrutura comunitária será afetada. Nesse sentido, o FIII, que é impactado, apresentou uma estrutura comunitária muito vulnerável, pois as quatro espécies com maior VI concentraram mais de $90 \%$ da comunidade de samambaias.

Por fim, dada a importância das funções deste tipo de formação vegetal e os impactos observados ao longo do rio Cadeia em Santa Maria do Herval, julga-se que a busca por estratégias eficientes para fins de recuperação destes fragmentos torna-se indispensável e são de caráter urgente.

\section{AGRADECIMENTOS}

Os autores agradecem a Coordenação de Aperfeiçoamento Pessoal de Nível Superior (CAPES) pelas bolsas de estudo concedidas para os dois primeiros autores e a Universidade Feevale pela infraestrutura disponibilizada para a realização deste estudo. 


\section{REFERÊNCIAS}

ATHAYDE-FILHO, F. P.; AGOSTINHO, A. A. Pteridoflora de duas veredas no município de Campinápolis, Mato Grosso, Brasil. Pesquisas, Botânica, v. 56, p. 145-160, 2005.

BARBOUR, M. T.; GERRITSEN, J.; SNYDER, B. D.; STRIBLING, J. B. Rapid bioassessment protocols for use in streams and wadeable rivers: periphyton, benthic macroinvertebrates and fish. 2. ed. Washington, D.C: USEPA, 1999.

BARRELLA, W.; PETRERE JR., M.; SMITH, W. S.; MONTAG, L. F. A. As relações entre as Matas ciliares, os rios e os peixes. In: RODRIGUE, R. R.; LEITÃO FILHO, H. F. Matas ciliares: conservação e recuperação. São Paulo: EDUSP/FAPESP, 2000. p. 187208.

BIZZO, M. R. O.; MENEZES, J.; ANDRADE, S. F. Protocolos de avaliação rápida de rios (PAR). Caderno de Estudos Geoambientais - CADEGEO, v. 4, n. 1, p. 5-13, 2014.

BONNET, A. Caracterização fitossociológica das bromeliáceas epifíticas e suas relações com os fatores geomorfológicos e pedológicos da planície do rio Iguaçu, Paraná, Brasil. 2006. 289f. Tese (Doutorado em Engenharia Florestal) - Universidade Federal do Paraná, Brasil, 2006.

BRASIL. Lei $\mathbf{n}^{0}$ 12.651, de 25 de maio de 2012. Dispõe sobre a proteção da vegetação nativa e dá outras providências. 2012. Disponível em: http://www.planalto.gov .br/ccivil_03/_Ato2011-2014/2012/Lei/L12651.htm. Acesso em: 12 jan. 2015.

CALLISTO, M.; FERREIRA, W.; MORENO, P.; GOULART, M. D. C.; PETRUCIO, M. Aplicação de um protocolo de avaliação rápida da diversidade de habitats em atividades de ensino e pesquisa (MG-RJ). Acta Limnologica Brasiliense, v. 14, n. 1, p. 91-98, 2002.

CONDACK, J. P. S.; SYLVESTRE, L. S. Structure of fern community in the high mountain forest of Itatiaia National Park, Brazil. In: VERMS, S. C.; KHULLAR, S. P.; CHEEMA, H. K. (Eds.). Perspective in Pteridophytes. Lucknow: Bishen Singh Mahendra Pal Singh, 2009, p. 113-126.

COSTA, F. R. C.; MAGNUSSON, W. E.; LUIZAO, R. C. Mesoscale distribution patterns of Amazonian understorey herbs in relation to topography, soil and watersheds. Journal of Ecology, v. 93, p. 863-878, 2005. http://dx.doi.org/10.1111/j.1365-2745.2005.01020.x

DIAS, R. M.; SALVADOR, N. N. B.; BRANCO, M. B. C. Identificação dos níveis de degradação de matas ripárias com o uso de SIG. Floresta e Ambiente, v. 21, n. 2, p. 150-161, 2014. http://dx.doi.org/10.4322/floram.2014.032

DIESEL, S.; SIQUEIRA, J. C. Estudo fitossociológico herbáceo/arbustivo da mata ripária da bacia hidrográfica do rio dos Sinos, Rio Grande do Sul. Pesquisas, Botânica, v. 42, n. 2 , p. 205-257, 1991.

FERNANDES, I. Taxonomia dos representantes de Dicksoniaceae no Brasil. Pesquisas, Botânica, v. 50, p. 5-26, 2000.

FORSTHOFER, M.; ATHAYDE-FILHO, F. P. A. Florística e Aspectos Ecológicos de Samambaias e Licófitas ao Longo do córrego Cachoeirinha, Nova Xavantina-MT. Pesquisas, Botânica, v. 63. p. 149-164, 2012. 
FRAGA, L. L.; SILVA, L. B.; SCHMITT, J. L. Composição e distribuição vertical de pteridófitas epifíticas sobre Dicksonia sellowiana Hook. (Dicksoniaceae), em Floresta Ombrófila Mista, no Sul do Brasil. Biota Neotrópica, v. 8, n. 4, p. 123-129, 2008.

FRANZ, I.; SCHMITT, J. L. Blechnum brasiliense Desv. (Pteridophyta, Blechnaceae): estrutura populacional e desenvolvimento da fase esporofítica. Pesquisas, Botânica, v. 56, p. 173-184, 2005.

GREGORY, S. V.; SWANSON, F. J.; McKEE, W. A.; CUMMINS, K. W. An ecosystem perspective of riparian zones. BioScience, v. 41, n. 8, p. 540-551, 1992. http://dx.doi.org/10.2307/1311607

HAMMER, O.; HARPER, D. A. T.; RYAN, P. D. Paleontological Statistics - PAST. Version 1.18. 2001. Disponível em: http://folk.uio.no/ohammer/past. Acesso em: jul. 2015.

HANNAFORD, M. J.; BARBOUR, M. T.; RESH, V. H. Training reduces observer variabillity in visual-based assessments of stream habitat. Journal of the North American Benthological Society, v. 4, p. 853-860, 1997. http://dx.doi.org/10.2307/1468176

KERSTEN, R. A.; KUNIYOSHI, Y. S. Conservação das florestas na bacia do alto Iguaçu, Paraná - Avaliação da comunidade de epífitas vasculares em diferentes estágios serais. Floresta, v. 39, n. 1, p. 51-66, 2009.

KREUTZ, C.; ATHAYDE-FILHO, F. P.; FERNANDES, L. R.; FORSTHOFER, M. Análise da distribuição espacial da flora pteridofítica em dois córregos da Bacia do Rio Pindaíba, MT. In: JORNADA CIENTÍFICA DA UNEMAT, 2., 2009, Barra do Bugres. Anais... Barra do Bugres: Unemat, 2009. 1 CD-ROM.

KREUTZ, C.; ATHAYDE-FILHO, F. P. Aspectos ecológicos da Flora Pteridofítica do Córrego Caveira, Barra do Garças - MT. In: CONGRESSO DE ECOLOGIA DO BRASIL, 9., São Lourenço. Anais... São Lourenço, 2009. p. 1-4.

LORSCHEITTER, M. L.; ASHRAF, A. R.; WINDSCH, P. G.; MOSBRUGGER, V. Pteridophyte spores of Rio Grande do Sul flora, Brazil. Part II. Palaeontographica, v. 251, p. 71-235. 1999.

MALLMANN, I. T.; SCHMITT, J. L. Riqueza e composição florística da comunidade de samambaias na mata ciliar do Rio Cadeira, Rio Grande do Sul, Brasil. Ciência Florestal, v. 24, n. 1, p. 97-109, 2014. http://dx.doi.org/10.5902/1980509813327

MCDONNELL, M. J.; PICKETT, S. T. A. Ecosystem structure and function along urbanrural gradient: an unexploited opportunity for ecology. Ecology, v. 71, n. 4, p. 12321237, 1990. http://dx.doi.org/10.2307/1938259

MORAN, R. C. Diversity, biogeography, and floristics. In: RANKER, T. A.; HAUFLER, C. H. (Eds.). Biology and evolution of ferns and lycophytes. New York: Cambridge University Press, 2008. p. 367-394.

MUELLER, C. C. Gestão de matas ciliares. In: LOPES, I. V.; BASTOS FILHO, G. S.; BILlER, D; BALE, M. (Orgs.). Gestão Ambiental no Brasil: experiência e sucesso. Rio de Janeiro: Fundação Getúlio Vargas, 1996. p. 185-214. 
MYNSSEN, C. M.; WINDISCH, P. G. Pteridófitas da Reserva Rio das Pedras, Mangaratiba, RJ, Brasil. Rodriguésia, v. 55, n. 85, p. 125-156, 2004.

http://www.jstor.org/stable/23497603

OLIVEIRA-FILHO, A. T.; RATTER, J. A. A. Study of the origin of central Brazilian forests by the analysis of plant species distribution patterns. Edinburg Journal of Botany, v. 52, n. 2, p. 141-194, 1995. http://dx.doi.org/10.1017/S0960428600000949

PACIENCIA, M. L. B.; PRADO, J. Distribuição espacial da assembléia de pteridófitas em uma paisagem fragmentada de Mata Atlântica no sul da Bahia, Brasil. Hoehnea, v. 32, n. 1, p. 103-117, 2005.

PEEL M. C; FINLAYSON B. L.; MCMAHON T. A. Updated world map of the KöppenGeiger climate classification. Hydrology and Earth System Science, v. 11, $n$. 5, p. 1633-1644, 2007.

PRADO, J.; SYLVESTRE, L. Samambaias e licófitas. In: INSTITUTO DE PESQUISAS JARDIM BOTÂNICO DO RIO DE JANEIRO. Lista de espécies da flora do Brasil. Rio de Janeiro, 2015. Disponível em: http://reflora.jbrj.gov.br/jabot/floradobrasil/ FB128483>. Acesso em: jul. 2015.

RIO GRANDE DO SUL. Decreto Estadual no 52.109, de 01 de dezembro de 2014. Declara as espécies da flora nativa ameaçadas de extinção do Estado do Rio Grande do Sul. Diário Oficial [do] Estado, Porto Alegre, n. 223, 02 dez. 2014, p. 2-11.

RIO GRANDE DO SUL. Secretaria do Ambiente e Desenvolvimento Sustentável - SEMA. Bacia hidrográfica do Rio Caí. 08 set. 2010. Disponível em: http://www.sema.rs.gov.br/conteudo.asp?cod_menu=56\&cod_conteudo=5864. Acesso em: jul. 2015.

RODRIGUES, A. S. L.; CASTRO, P. T. A. Protocolos de avaliação rápida: instrumentos complementares no monitoramento dos recursos hídricos. Revista Brasileira de Recursos Hídricos, v. 13, n. 1, p. 161-170, 2008.

RODRIGUES, R. R.; GANDOLFI, S. Conceitos, tendências e ações para a recuperação de florestas ciliares. In: RODRIGUES, R. R.; LEITÃO FILHO, H. F. Matas ciliares: conservação e recuperação. São Paulo: EDUSP/FAPESP, 2000. p. 235-248.

RODRIGUES, R. R.; NAVE, A. G. Heterogeneidade florística das matas ciliares. In: RODRIGUES, R. R.; H. F. LEITÃO-FILHO. Matas Ciliares: conservação e recuperação. São Paulo: EDUSP/FAPESP, 2000. p. 45-71.

RODRIGUES, A. S. L.; CASTRO, P. T. A.; MALAFAIA, G. Utilização dos protocolos de avaliação rápida de rios como Instrumentos complementares na gestão de bacias hidrográficas envolvendo aspectos da geomorfologia fluvial: uma breve discussão. Enciclopédia Biosfera, v. 6, n. 11, p. 1- 9, 2010.

http://www.repositorio.ufop.br/handle/123456789/4162

SALINO, A. Estudos Taxonômicos na família Thelyptetidaceae (Polypodiopsida) no estado de São Paulo, Brasil. 2000. 327f. Tese (Doutorado em Biologia Vegetal) Instituto de Biologia, Universidade Estadual de Campinas, Campinas, 2000. 
SARMENTO, E. C.; WEBER, E.; HASENACK, H. Avaliação da cobertura vegetal na microbacia Feitoria/Cadeia utilizando técnicas de geoprocessamento. 2001. Disponível em: http://www.ecologia.ufrgs.br/labgeo/artigos/cadeia.pdf. Acesso em Julho de 2015.

SCHMITT, J. L.; SCHNEIDER, P. H.; WINDISCH, P. G. Crescimento do cáudice e fenologia de Dicksonia sellowiana Hook. (Dicksoniaceae) no sul do Brasil. Acta Botanica Brasilica, v. 23, n. 1, p. 289-291, 2009. http://dx.doi.org/10.1590/S010233062009000100030

SILVA, I. A. A.; PEREIRA, A. F. N.; BARROS, I. C. L. Edge effects on fern community in an Atlantic Forest remnant of Rio Formoso, PE, Brazil. Brazilian Journal of Biology, v. 71, n. 2, p. 421-430, 2011. http://dx.doi.org/10.1590/S1519-69842011000300011

SILVA, V. L. Efeito de borda em Floresta com Araucária com diferentes graus de perturbação antrópica: uma análise da comunidade de samambaias e licófitas, de fatores microclimáticos e edáficos. 2013. 51f. Dissertações (Mestrado em Qualidade Ambiental) - Universidade Feevale, Novo Hamburgo, 2013.

SMITH, A. R.; PRYER, K. M.; SCHUETTPELZ, E.; KORALL, P.; SCHNEIDER, H.; WOLF, P. G. Fern classification. In: RANKER, T. A.; HAUFLER, C. H. (Eds.). Biology and Evolution of Ferns and Lycophytes. Cambridge: Cambridge University Press, 2008. p. 417-467.

THOMAZ, S. M.; PAGIORO, T. A.; BINI, L. M.; ROBERTO, M. C.; ROCHA, R. R. A. Limnology of the Upper Paraná Floodplain habitats: patterns of spatio-temporal variations and influence of the water levels. In: AGOSTINHO, A. A.; RODRIGUES, L.; GOMES, L.C.; THOMAZ, S. M.; MIRANDA, L. E. Structure and functioning of the Paraná River and its floodplain. Maringá: EDUEM, 2004. V. 1. p. 37-42.

THOMAZ, S. M. Fatores ecológicos associados à colonização e ao desenvolvimento de macrófitas aquáticas e desafios de manejo. Planta Daninha, v. 20, p. 21-33, 2002. http://dx.doi.org/10.1590/S0100-83582002000400003

TRYON, R. M.; TRYON, A. F. Ferns and allied plants with special reference to Tropical America. New York: Springer Verlag, 1982. 857p.

VUONO, Y. S. Inventário fitossociológico. In: SYLVESTRE, L. S.; ROSA, M. M. T. (Orgs.). Manual metodológico para estudos botânicos na Mata Atlântica. Rio de Janeiro: Seropédica, 2002. p. 51-65.

WINDISCH, P. G. Hymenophyllaceae (polypodiopsida) no estado do Rio Grande do Sul. Pesquisas, Botânica, v. 65, p. 15-48, 2014.

WINDISCH, P. G. Pteridófitas da região norte-ocidental do estado de São Paulo: guia para excursões. 2. ed. São José do Rio Preto: Universidade Estadual Paulista, 1992. $110 \mathrm{p}$.

WINDISCH, P. G. Towards assaying biodiversity in Brazilian pteridophytes. In: BICUDO, C. E. M.; MENEZES, N. A. (Eds.). Biodiversity in Brazil: a first approach. São Paulo: CNPq. 1996. p. 109-117. 